Direito do Estado - Rita de C. Resquetti Tarifa Espolador

\title{
JURISDIÇÃO CONSTITUCIONAL E DEMOCRACIA NA CONSTITUIÇÃO BRASILEIRA: ENTRE O ATIVISMO E A AUTO-CONTENÇÃO \\ BREVE ANÁLISE SOBRE O PAPEL DO JUDICIÁRIO FRENTE ÀS QUESTÕES LIGADAS À LIBERDADE DE PESQUISA E À MANIPULAÇÃO DA VIDA HUMANA*
}

\author{
Rita de C. Resquetti Tarifa Espolador ${ }^{* *}$
}

\begin{abstract}
RESUMO
Busca-se analisar o papel do Poder Judiciário frente às diversas questões envolvendo a manipulação genética humana e as pesquisas realizadas no Brasil, nos dias atuais, para tal fim. Utilizando-se dos conceitos de ativismo e auto-contenção, verifica-se, a partir de alguns constitucionalistas, de que forma o Judiciário deve posicionar-se diante do desenvolvimento da pesquisas envolvendo os seres humanos.
\end{abstract}

SUMÁRIO: 1 INTRODUÇÃO; 2 PREVISÃO CONSTITUCIONAL SOBRE A LIBERDADE DE PESQUISA; 3 O PODER JUDICIÁRIO COMO INTÉRPRETE DA CONSTITUIÇÃO: VISÃO DA DOUTRINA CONSTITUCIONAL; 3.1 AS VISÕES PROCEDIMENTALISTA E SUBSTANCIALISTA ESTADUNIDENSES; 3.2 O PROBLEMA DA UNIDADE DA SOLUÇÃO JUSTA EM DWORKIN E HABERMAS; 3.3 A DEMOCRACIA DELIBERATIVA EM NINO; 3.4 NEOCONSTITUCIONALISMO EM SusANA POZZOLO, COMANDUCCI E PRIETO SANCHÍS; 3.5 O CARÁTER CONTRAMAJORITÁRIO DO PODER JUDICIAL EM GARGARELLA; 4 O PAPEL DO PODER JUDICIÁRIO FRENTE AOS AVANÇOS DA CIÊNCIA GENÉTICA E A MANIPULAÇÃO DA VIDA HUMANA: LIMITES E POSSIBILIDADES; 5 CONSIDERAÇÕES FINAIS; REFERÊNCIAS.

\footnotetext{
* Paper apresentado como requisito parcial para a aprovação na disciplina do Curso de Doutorado ministrada pelo Prof. Dr. Clèmerson Clève.

** Doutoranda em Direito Civil pela UFPR (Orientador: professor Eduardo de Oliveira Leite). Professora de Direito Civil na UNOPAR (Universidade Norte do Paraná). Advogada em Londrina-PR e-mail: rita.tarifa@gmail.com
} 
Revista Eletrônica do CEJUR, Curitiba-PR, a. 2, v. 1, n. 3, ago./dez. 2008

\section{INTRODUÇÃO}

A liberdade de pesquisa é pressuposto da atividade científica. Nesse contexto, o surgimento de novas tecnologias de manipulação da vida (avanços na ciência genética, por exemplo) trouxe consigo normas jurídicas visando à proteção do ser humano.

Por vezes, os avanços da biotecnologia vêm provocando perplexidade no mundo jurídico. A discussão atual segue com foco na recente aprovação da Lei de Biossegurança, que tratou, dentre outros assuntos, da questão da limitação da utilização de células-tronco embrionárias para fins de clonagem terapêutica.

A inviolabilidade da pessoa humana encontra-se ameaçada, na atualidade, por manipulações excepcionais para o desenvolvimento da pesquisa científica, decorrentes, em grande parte, da intenção lucrativa.

Quando se analisa a questão da possibilidade de manipulação de genes, observa-se que as vertentes criadas a partir de tal ato são várias: divulgação dos resultados para fins científicos, utilização em fabricação de fármacos e até mesmo a comercialização do material. Deve-se analisar de que forma o Direito protege a vida humana no marco da evolução dos denominados direitos fundamentais. De fato, a denominada "quarta dimensão" dos direitos fundamentais tem como núcleo os avanços da ciência genética. A dignidade da pessoa humana é, nesse contexto, fundamentovalor que deve ser considerado, ainda que não seja o único.

A vida humana é um bem jurídico, portanto, merece guarida do ordenamento. É, de fato, a vida do ser que manifesta uma condição que lhe é inerente, reafirmando sua natureza de ser social, que procura a cada dia atingir estágios mais avançados de desenvolvimento.

O desenvolvimento da sociedade sempre se orientou tendo como valor primordial a pessoa e sua dignidade. Os demais valores (liberdade, democracia, justiça social, dentre outros) acabam sendo interpretados tendo como núcleo a própria pessoa. Todavia, não se pode perder de vista que o avanço da sociedade restou por muitas 


\section{JURISDIÇÃo CONSTITUCIONAL E DEMOCRACIA NA CONSTITUIÇÃo BRASILEIRA: ENTRE O ATIVISMO E A AUTO-CONTENÇÃo}

vezes, por meio da normatização estatal, no perfazimento de desigualdades entre as pessoas, de pressões exercidas sobre os menos favorecidos. A evolução dos direitos fundamentais deu lugar a uma concepção de universalidade, que trouxe razão e lógica aos estatutos constitucionais.

\section{PREVISÃO CONSTITUCIONAL SOBRE A LIBERDADE DE PESQUISA}

A realização de pesquisas científicas envolvendo seres humanos vem sendo alvo de discussões acirradas, porquanto atualmente percebem-se alguns "vazios jurídicos", dos quais decorrem implicações sérias para os países que têm desenvolvido tais pesquisas, como o Brasil. A pesquisa envolvendo a biotecnologia tem tido tamanha importância, pois se sabe que os novos conhecimentos produzidos por essa área são passíveis de provocar radicais transformações no trato do homem com a vida, incluindo aí mudanças de concepção sobre a própria vida humana e adoção de novas práticas destinadas a preservá-la, prolongá-la, alterá-la, ainda que exista a dificuldade em precisar tais mudanças. $\mathrm{O}$ interesse coletivo no irrenunciável progresso da ciência médica de um lado e o interesse individual, o respeito à pessoa humana, em seus bens existenciais de vida, dignidade e integridade física etc., de outro, exigem um repensar sobre o uso das modernas tecnologias e uma regulamentação jurídica de seus limites. Neste contexto, o Judiciário exerce papel fundamental, que deve ser analisado com vistas à aplicação da concepção sobre a tensão estudada na disciplina, envolvendo a democracia representativa e o ativismo judicial.

A Constituição Federal de 1988 prevê duas espécies de pesquisas: científica e tecnológica. A pesquisa científica básica receberá tratamento prioritário do Estado, tendo em vista o bem público e o progresso das ciências. A pesquisa tecnológica voltar-se-á preponderantemente para a solução dos problemas brasileiros e para o desenvolvimento do sistema produtivo nacional e regional, conforme dispõe o artigo 218. Quanto ao Genoma Humano, o texto constitucional o protege, como parte do 
meio ambiente (art. 225, parágrafo $1 .^{\circ}$, inciso II).

\section{O PODER JUDICIÁRIO COMO INTÉRPRETE DA CONSTITUIÇÃO: VISÃO DA DOUTRINA CONSTITUCIONAL}

O estudo das diferentes visões doutrinárias feito na disciplina possibilitou focar o objeto de análise na evidente tensão (expressão citada por alguns dos autores estudados) estabelecida entre os limites da jurisdição constitucional, os direitos fundamentais e a democracia.

As discussões estabelecidas na disciplina deram-se em torno da análise acerca da intersecção entre a Política e o Direito e, consequentemente, do papel do Poder Judiciário e seus limites de atuação em um regime democrático.

Verificou-se a diversidade de pensamentos dos autores estudados, ora defendendo uma atuação indissociável do magistrado com o campo político, ora sustentando um papel de garantidor, apenas, do processo democrático, afastando-se de qualquer relação de poder envolvendo o processo político de dado país.

Não se pode deixar de citar que outra discussão com a mesma relevância deuse em relação à representatividade, e o significado das decisões de uma "maioria", não necessariamente correta. Nesse contexto, como garantir o direito das minorias é uma das questões que se impõem.

Algumas correntes diferentes podem ser analisadas, ainda que brevemente, com vistas à sua utilização no estudo do problema envolvendo a opção entre o ativismo e auto-contenção em matéria constitucional de liberdade de pesquisas científica e tecnológica envolvendo a manipulação genética humana.

As obras analisadas, estadunidenses, européias e sul-americanas, tiveram a possibilidade de estabelecer uma evolução do pensamento constitucional acerca do núcleo da discussão ali pretendida, bem como possibilitaram uma análise da situação 


\section{JURISDIÇÃo CONSTITUCIONAL E DEMOCRACIA NA CONSTITUIÇÃo BRASILEIRA: ENTRE \\ O ATIVISMO E A AUTO-CONTENÇÃO}

brasileira. Em seguida, tem-se, aleatoriamente, o pensamento extraído de algumas das obras.

\subsection{AS VISÕES PROCEDIMENTALISTA E SUBSTANCIALISTA ESTADUNIDENSES}

Os procedimentalistas vinculam o Judiciário à organização formal das garantias da democracia representativa, afastando-se da política, que seria organizada e executada nos outros níveis de poderes.

Para Bruce Ackerman, por exemplo, o Judiciário tem caráter conservacionista e não ativista, tendo a Suprema Corte um papel fiscalizatório e de inspeção das atividades dos demais poderes, visando à defesa da vontade popular e o fortalecimento do sistema em épocas de política usual e vulnerabilidade. O autor é contrário ao posicionamento de Rawls e Dworkin, defendendo a idéia de que os direitos fundamentais não são direitos substantivos, mas procedimentais, já que todos os indivíduos têm o direito básico de participar de um processo político deliberativo, no qual determinam o conteúdo substantivo dos demais direitos fundamentais. Propõe um modelo de democracia dualista, distinguindo as políticas rotineiras e as transformações do sistema. Para ele, a Constituição busca distinguir duas decisões diferentes que podem ser tomadas em uma democracia: a primeira, pelo povo e a segunda pelo governo.

Sinteticamente, para os procedimentalistas, os tribunais constitucionais são garantidores dos direitos fundamentais de participação política, de acesso ao discurso político, tendo o Judiciário legitimidade para restringir a vontade da maioria somente como guardião do procedimento.

Os substancialistas, por outro lado, respeitam os limites formais de atuação dos poderes, mas não há um afastamento do Judiciário na atuação da manutenção e defesa dos direitos fundamentais. Tal teoria admite a existência de direitos 
fundamentais que representam valores mínimos escolhidos pelo povo, no momento constituinte que perduram com o tempo e que devem ser protegidos, inclusive contra as maiorias eventuais.

\subsection{O PROBLEMA DA UNIDADE DA SOLUÇÃO JUSTA EM DWORKIN E HABERMAS}

Ambos os autores merecem destaque nesta breve exposição, porquanto são autores de obras específicas, envolvendo as diversas formas de manipulação da vida, com visões antagônicas.

Ronald Dworkin expõe que a discricionariedade não deve existir, porque o juiz não está legitimado a criar o Direito, pois, neste caso, está produzindo um Direito ex post factum, lesionando a segurança dos que recorrem ao Judiciário. Onde não chegam as normas explícitas, chegam os princípios, que unem o Direito e a Moral. Existe, assim, uma solução correta para cada caso.

Em "O Domínio da Vida" (p.102 e seguintes), o autor aponta que: "Se pensarmos porém, que a vida de qualquer organismo humano, inclusive a do feto, tem valor intrínseco a despeito de também ter ou não, valor instrumental ou pessoal - se tratarmos qualquer forma de vida humana como algo que devemos respeitar, reverenciar e proteger por ser maravilhosa em si mesma, teremos então que o aborto é moralmente problemático". O princípio de que a vida humana, inclusive a de um embrião recém-formado, é inviolável, deve ser objetado e a santidade da vida é um valor extremamente controverso e contestável, pela concepção dworkiniana.

Para Habermas, não existe organização sócio-cultural de vida que não esteja comprometida com a realização de ações comunicativas. A tarefa de justificação de normas fundamentais requer um esforço cooperativo, portanto. A imparcialidade, nesse contexto, seria um pressuposto formal. 


\section{JURISDIÇÃo CONSTITUCIONAL E DEMOCRACIA NA CONSTITUIÇÃo BRASILEIRA: ENTRE O ATIVISMO E A AUTO-CONTENÇÃO}

Tratando especificamente da imunização de técnica e da ciência de controles éticos, Habermas, em "O futuro da natureza humana", volta à atenção para a eugenia liberal, opondo-se ao desenvolvimento científico sem qualquer controle ético. É importante perceber que para Habermas, a dignidade de pessoa humana é argumento simplista e insuficiente par resolver questões vinculadas à legitimidade da ciência. Tampouco se podem proceder a ponderações entre interesses da pessoa humana concreta e do embrião.

Segundo o autor, meios e fins, por uma exigência democrática, são definidos originariamente pelo legislador político, cabendo ao Judiciário tão somente verificar se a medida tem caráter discriminatório ou se viola direitos fundamentais.

\subsection{A DEMOCRACIA DELIBERATIVA EM NINO}

Santiago Nino aponta as três dimensões do constitucionalismo, quais sejam a democracia, os direitos e a constituição histórica, bem como tenta estabelecer a intersecção entre elas, considerando o papel desempenhado na argumentação prática que conduz à justificação de ações e decisões. Para ele, a moral antecede a democracia. Tal ponto é pertinente em se tratando de julgamentos envolvendo o biodireito, já que não há como dissociar os aspectos morais refletidos.

O juiz está sujeito a regras e procedimentos para assegurar sua imparcialidade. A decisão não deveria, para Nino, ser obrigatória em outros casos, a menos que seja tomada em um processo no qual todos os afetados possam participar.

\subsection{NEOCONSTITUCIONALISMO EM SUSANA POZZOLO, COMANDUCCI E PRIETO SANCHÍS}

Os neoconstitucionalistas adotam a idéia de moral universal ou objetiva, que 
seria um conjunto de princípios referentes ao comportamento humano justo em si mesmo, desvinculado da concepção de bem e mal.

Nesse contexto, a atividade do jurista deve ser tendente à individualização do Direito, enquanto o magistrado deve ter em mente a necessidade de individualização do conteúdo do Direito. Percebe-se, portanto, a possibilidade da admissão da teoria positivista para a análise do Direito no Estado Constitucional, porém sob "roupagem" diversa.

Sanchís ressalta que o personagem principal da denominada constituição transformadora não é mais o legislador, e sim o magistrado. Esta concepção do judicialismo merece reflexão aprofundada a fim de que a atuação dos juízes seja limitada e não desfigure a busca pelo efetivo ideal de justiça.

\subsection{O CARÁTER CONTRAMAJORITÁRIO DO PODER JUDICIAL EM GARGARELLA}

Roberto Gargarella tem como núcleo de sua obra a questão: como podem, em uma democracia, juízes não eleitos pelo povo (destituídos de representatividade popular), dotados de estabilidade em seus cargos, declarar inválida (em última instância) uma lei aprovada pelos representantes do povo?

Criticando Ackerman, afirma que aquela teoria relega às maiorias um papel relativamente secundário e passivo e deposita excessiva confiança no sistema de freios e contrapesos na tarefa de criação legislativa. Defende, portanto, a democracia deliberativa, pois facilita e promove a discussão pública, tendo o condão de alcançar a imparcialidade. Ao Judiciário cabe a tarefa de resguardar os procedimentos democráticos. 
JURISDiÇÃo CONSTITUCIONAL E DEMOCRACIA NA CONSTITUIÇÃo BRASILEIRA: ENTRE

O ATIVISMO E A AUTO-CONTENÇÃO

\section{O PAPEL DO PODER JUDICIÁRIO FRENTE AOS AVANÇOS DA CIÊNCIA GENÉTICA E A MANIPULAÇÃO DA VIDA HUMA̛NA: LIMITES E POSSIBILIDADES}

Questão geral que se impõe ao se estudar o presente tema, reside no real papel do Poder Judiciário na implementação dos valores substantivos exigidos na Constituição de 1988.

Em sede de decisões envolvendo a liberdade de pesquisa genética, por exemplo, em que pese a previsão constitucional e o interesse do Estado na matéria, a regulamentação brasileira, por ora, está distante de um consenso.

Tem-se a legislação civilista prevendo formas protetivas da personalidade humana e algumas leis especificando procedimentos de pesquisa, como a Lei de Biossegurança, recentemente modificada, que estabelece, a seu modo, limites na realização de pesquisas envolvendo seres humanos.

Diante de tal quadro, percebe-se que o Judiciário encontra-se um tanto quanto perdido na solução de questões envolvendo a manipulação da vida, fato passível de comprovação com a realização de audiência pública no Supremo Tribunal Federal visando à discussão sobre o início da vida. Naquela ocasião, foram chamados 26 cientistas de diversas áreas (medicina, genética, bioética, antropologia etc.) que se posicionaram diversamente em relação à possibilidade de utilização de células-tronco extraídas de embriões para a realização de pesquisas científicas.

A discussão se originou pela necessidade de julgamento de ação direta de inconstitucionalidade (proposta pela Procuradoria Geral da República) que contesta a utilização de referidas células, com base na Lei 11.105/2005 (Biossegurança), sustentando sua tese no ferimento do direito constitucional à vida e à dignidade humana. Na época, a presidente do STF afirmou que julgar matéria tão difícil seria um exercício de humildade.

Recentemente, verificou-se o encerramento da discussão, ao menos aquela que envolvia a possibilidade de realização de pesquisas com células-tronco embrionárias, 
porém, os problemas estão longe do fim.

Como afirma Plauto Faraco de Azevedo (p.21) "Em nome da autonomia da ciência do Direito, assim construída e limitada, aferram-se os juristas àquilo que é puramente jurídico. Às teimosas investidas de um mundo em vertiginosa mutação, às crises sociais sucessivas, ao clamor da vida que reclama nova configuração políticojurídica, inspirada pela ética da solidariedade em um universo cada vez mais interdependente, os juristas respondem com o refinamento de suas técnicas analíticodescritivas, encarando o drama humano como o óculo de um aparato conceitual que lhes garante um confortável afastamento do campo de luta".

Tal crítica demonstra a situação do Judiciário, que parece pedir socorro e auxílio à sociedade para fins de alcance (se é que isto seria possível) de um consenso nas questões vinculadas à manipulação da vida humana.

Vários integrantes do Judiciário, à época da realização da audiência pública, evento sem precedentes na história brasileira, afirmaram que a tentativa era a de padronização do conceito de vida, sob a ótica jurídica. Ou seja, agir diante de omissão legislativa.

Mas, diante das diferentes posições no que tange ao ativismo ou à autocontenção aqui brevemente delimitadas, impõe-se um posicionamento quanto à postura do Judiciário na solução dos problemas envolvendo o biodireito. Deverá ele ser chamado a solucionar, por exemplo, questões individuais envolvendo a admissibilidade de pesquisas que utilizem células-tronco embrionárias? Deverá se manifestar em processos autônomos, utilizando-se de suas prerrogativas?

É importante ao menos tentar delimitar a atuação legítima do Supremo Tribunal Federal em questões como as advindas da interpretação do artigo quinto da Lei de Biossegurança. Não se pode esquece que há duas situações: a) aquelas em que, não havendo manifestação expressa do legislador, o Judiciário deve chegar a uma resposta; b) aquelas em que, apesar de haver disposição legal, são alvos de considerável desacordo moral na sociedade.

Esta última situação envolve a expressão consenso (alcançado após um 


\section{JURISDIÇÃo CONSTITUCIONAL E DEMOCRACIA NA CONSTITUIÇÃO BRASILEIRA: ENTRE \\ O ATIVISMO E A AUTO-CONTENÇÃo}

exercício de discussão coletiva no processo de conhecimento de assuntos morais, conforme o entendimento de Nino), buscada pela Constituição, ainda que não satisfatoriamente. O Judiciário pode declarar a invalidade e afastar a eficácia de normas atentatórias ao texto constitucional. Em que pese tal legitimidade, não pode exercer preferências políticas. Eis aqui o ponto que poderia ser adequado ao núcleo da discussão realizada na disciplina de Direito Constitucional: a tensão entre as duas situações narradas. Aprovou-se o dispositivo supramencionado legitimamente, por meio de decisão majoritária legítima. Existiria incompatibilidade com o texto constitucional? Em havendo, qual deveria ser a postura do Tribunal?

Não se pretende alcançar respostas conclusivas neste trabalho, mas demonstrar que as visões procedimentalistas e substancialistas, desde que corretamente interpretadas, podem servir ao afastamento da incompatibilidade entre a jurisdição constitucional e a democracia, aqui tratado especificamente no que pertine ao regramento envolvendo a pesquisa com embriões e os problemas dele advindos.

Não há como afirmar que a Constituição Federal "responda tudo", ou seja, cale todos os anseios da sociedade. Todavia, pode-se dizer que a Constituição brasileira foi sábia ao cuidar de direitos que dizem respeito ao exercício da democracia. O Judiciário, por sua vez, não tem o papel de "guia" da sociedade, mas insere-se em um caráter de interpretação. Deve, assim, garantir condições para a deliberação.

A compreensão da democracia brasileira, e, consequentemente dos problemas dela advindos, é tarefa difícil e que requer cautela, em razão de ter sido editada há menos de vinte anos. O Brasil vive uma história constitucional recente, na qual se inclui o corporativismo e outras questões que obstaculizam o alcance dos ideais de justiça almejados pelo Direito. 


\section{CONSIDERAÇÕES FINAIS}

A problemática entre o ativismo e o regime democrático deve ser analisada, nesta pequena reflexão, levando-se em conta alguns fatores, que apesar de não conclusivos, pretendem ao menos nortear as discussões: a) considera-se o magistrado o intérprete máximo da Constituição; b) sua atuação não pode nem deve ser ilimitada e dotada da alto grau de subjetividade em questões vinculadas à manipulação da vida por meio de experimentos e pesquisas; c) os dispositivos constitucionais atinentes à matéria devem se sobrepor; d) a existência de vazios jurídicos inegavelmente impõe uma atuação judicial contundente, mas que jamais pode se afastar dos reais interesses do povo; e) os juristas não podem se afastar do "campo de luta" quando em xeque interesses tão primordiais como a vida e suas diferentes formas de manipulação; f) a liberdade de pesquisa disposta no texto constitucional não é ilimitada, razão pela qual o Judiciário deve exercer papel de controle, seja em relação às normas infraconstitucionais, seja em relação a situações concretas a serem julgadas, na tentativa de proteger os valores fundamentais de um regime que busca a proteção integral da pessoa; g) o Judiciário deve preservar os direitos fundamentais do cidadão, sem, contudo, agir de modo a ultrapassar as barreiras existentes aos distintos poderes estatais; h) a atuação dos tribunais, inclusive no tocante às questões envolvendo a manipulação da vida, não deve se limitar excessivamente (auto-contenção), tampouco acarretar intervencionismo exacerbado e excessivamente discricionário (como comumente se tem verificado no Brasil em outras áreas); i) deve-se tentar buscar um ponto de equilíbrio quando em jogo a liberdade de investigação científica e outros valores igualmente tutelados constitucionalmente. Porém, não se pode usar como fundamentação exclusiva a dignidade da pessoa humana; j) a tensão entre a jurisdição constitucional, a democracia e os direitos fundamentais (aqui voltados à dicotomia liberdade de investigação e respeito à vida) pode ser afastada na medida em que o Judiciário conseguir vislumbrar as situações em que as deliberações democráticas não consistirem efetivamente na observância aos valores essenciais protegidos primordialmente. 


\section{JURISDIÇÃo CONSTITUCIONAL E DEMOCRACIA NA CONSTITUIÇÃo BRASILEIRA: ENTRE O ATIVISMO E A AUTO-CONTENÇÃo}

\section{REFERÊNCIAS}

ACKERMAN, Bruce. Nós, o povo soberano. Fundamentos do Direito Constitucional. Del Rey Internacional. Belo Horizonte, 2006. Tradução de Mário Raposo de Mello.

AZEVEDO, Plauto Faraco de. Crítica à dogmática e hermenêutica jurídica. Porto Alegre: Fabris, 1989.

DWORKIN, Ronald. Domínio da vida. São Paulo: Martins Fontes, 2003.

HABERMAS, J. O futuro da natureza humana. A caminho da eugenia liberal? Trad. Karina jannini. São Paulo: Martins Fontes, 2004.

POZZOLO, Suzanna; DUARTE, Écio Oto Ramos. Neoconstitucionalismo $e$ positivismo jurídico: as faces da teoria do Direito em tempos de interpretação moral da Constituição. São Paulo: Landy, 2006. 